\title{
Sınıf Etkinliklerim Ölçeği’nin (SEÖ) Türk Kültürüne Uyarlanması: Geçerlik ve Güvenirlik Çalışması*
}

\section{Adaptation of My Classroom Activities Scale to Turkish Culture: Validity and Reliability Study}

\author{
Kaan Zülfikar DENIZ * * $\quad$ Adile Gülşah SARANLI ***
}

\begin{abstract}
$\ddot{O} \mathbf{z}$
Öğrencilerin sınıf etkinliklerine ilgi duymaları, etkinlik konularından zevk almaları, etkinliğin konusuyla ilgili seçim yapabilmeleri ve etkinlikler sırasında sınırlarını zorlayabilmeleri, üst düzey öğrenmelerin altında yatan temel unsurlardandır. Eğitsel etkinliğin ilgi çekici, zevkli, seçim yapabilmeye ve sınırları zorlamaya olanak tanıyan özelliklerinin olması, aynı zamanda 21. Yüzyılın eğitim sistemindeki neredeyse tüm eğitsel içerik, süreç ve üründe bulunmasını istediğimiz özelliklerdendir. Bu özelliklerin ölçülmesi de dolayısıyla büyük önem taşımaktadır. Bu çalışmanın amacı, Gentry ve Gable (2001) tarafından Amerika Birleşik Devletleri'nde geliştirilen; geliştirildiği kültürdeki farklı öğrenci gruplarına uygulanan ve ayrıca Kore, Çin ve Arap dillerine çevrilen ve Güney Kore kültürüne de uyarlama çalışması yapılmış olan Sınıf Etkinliklerim Ölçeği'nin Türk kültürüne uyarlamasını gerçekleştirmektir. Bu doğrultuda araştırma, 2015-2016 eğitim-öğretim yılında 3., 4., 5., 6., 7. ve 8. sınıflarda öğrenim gören toplam 214 öğrenciden elde edilen veri ile yürütülmüștür. Ölçeğin geçerlik çalışması kapsamında orijinal ölçek geliştirme çalışmasında elde edilen faktör yapısı Doğrulayıcı Faktör Analizi (DFA) ile test edilmiştir. Ayrıca geçerlik çalışması olarak madde-toplam korelasyonları ve boyutlar arası korelasyon analizleri gerçekleştirilmiştir. Ölçeğin güvenirlik çalışmasında Cronbach alfa güvenirlik katsayısı kestirilmiştir. Elde edilen bulgulara göre ölçeğin faktör yapısı orijinal ölçek geliştirme çalışmasına paralel olarak doğrulanmıştır. Ayrıca Cronbach alfa değerlerinin 0,82 ile 0,90 arasında olduğu görülmektedir. Yapılan bu çalışmalar ile ölçeğin, Türk kültüründe kullanımı için gerekli geçerlik ve güvenirlik kanıtları sağlanmış ve ölçek farklı çalışmalar için kullanılmak üzere alana kazandırılmıştır.
\end{abstract}

Anahtar Kelimeler: Sınıf etkinlikleri, ölçek uyarlama, doğrulayıcı faktör analizi

\begin{abstract}
Student interest in class activities, their enjoyment of activity topics, their ability to make choices about the activity topics, and opportunities for students to challenge themselves during activities are among basic components that support their higher level learning. Properties of educational activities that make them interesting, enjoyable, and challenging while allowing students with choices are also among properties that are known to be necessary in all educational content, processes, and products within educational systems of the 21st century. Consequently, measuring these properties is also of great importance. The goal of this study is to perform the Turkish adaptation of the My Class Activities Scale, developed by Gentry and Gable (2001) in the United States and subsequently adapted to the Korean, Chinese, and Arabic languages. To this end, data was collected from 214 students attending 3rd, 4th, 5th, 6th, 7th, and 8th grades during the 2015-2016 academic year. As part of the validity study for the scale, the factor structure obtained from the original development of the scale was tested using the Confirmatory Factor Analysis (CFA) method. Moreover, item-total correlation and inter-dimensional correlation analyses were also performed as part of the validity study. In studying the reliability of the scale, the Cronbach-Alpha reliability coefficients were estimated (Cronbach alpha values ranged between 0.82-0.90). Based on the results, the factor structure of the scale was verified in parallel with the original development work for the scale. In conclusion, the validity and reliability of using the scale in Turkey was established, contributing a new scale adaptation to the Turkish literature for use in different studies.
\end{abstract}

Keywords: Classroom activities, scale adaptation, confirmatory factor analysis

\footnotetext{
*Bu araştırma 115K814 kodlu TUBITAK projesi tarafindan desteklenmektedir.

** Doç.Dr., Ankara Üniversitesi, Eğitim Bilimleri Enstitüsü, Ankara-Türkiye, zlfkrdnz@yahoo.com

*** Yrd. Doç. Dr., TED Üniversitesi, Eğitim Fakültesi, Ankara-Türkiye, gsaranli@gmail.com
} 


\section{GİRIŞ}

Sınıf ortamında öğrencileri motive etmek ve sınıf disiplinini sağlayabilmek öğretmenler için önemli bir güçlük oluşturmaktadır. Sınıf disiplininin bozulması durumu başta öğretmenin, sonrasında ise ögrencilerin genel motivasyonlarını olumsuz etkiler. Motive olmayan öğrenciler ise genellikle düşük başarı göstermeye eğilimlidirler (Gentry \& Gable, 2001) ve sınıftaki ortamı bozarak kendi çalışmalarına odaklanmaya çalışan diğer öğrencileri olumsuz yönde (Gentry, Gable, 2001; Gentry, Rizza \& Owen, 2002) etkileyebilirler. Öğrencilerin sınıf ortamında gerçekleştirilen etkinliklere karş1 yönlendirilebilmeleri için bu etkinliklerin içeriğinin, uygulanmasındaki yöntemlerin ve ortaya çıkarılan ürünlerin ilgi çekici, zevkli, seçim yapabilmeye olanak sağlayan ve sınırlarını zorlayıcı niteliklerde olması çok önemlidir. Bu nitelikler öğrencilerin eğitim programını yaşamdan ayrı ve yapay bir biçimde algılamayıp, onunla bütünleşmelerini ve eğitim programında onları motive eden konuları bulmalarını sağlayacak şekilde dizayn edildiğinde hem akademik hem de Pratik hayatta en yüksek başarıya ulaşılmaktadır. Öğrencilerin sınıfta gerçekleştirdikleri etkinlikleri nasıl algıladıklarına ve onları öğrenme yolculuğunda nelerin motive ettiğine ilişkin bilgimizin olması, hem eğitimci hem de araştırmacıların, öğrencilerin öğrenmeye motive olmalarında hangi önemli basamakların yer teşkil ettiğini anlamalarını (Gentry, Gable \& Rizza, 2002; Middleton, 1995; Middleton, Littlefield \& Lehrer, 1992) ve daha da ötesi başarısızlık problemini önlemeyi (Matthews \& McBee, 2007) sağlayacak önemli adımlardan olacaktır. .

Alan yazındaki pek çok köklü eğitim kuramcısı ve araştırmacı, (Dewey, 1916; James, 1890; Renzulli, 1978; Ward, 1980; Whitehead, 1929) öğrencilerin ilgi alanlarının, onları öğrenmeye teşvik etmek için kullanılmasını önermişlerdir. Schiefele (1991) 'ilgi'yi belirli içerik alanlarında performans ve motivasyonu etkileyen yönlendirici bir güç olarak tarif etmiştir. Benzer bir şekilde, Whitehead (1929) ilgi olmadan zihinsel gelişim olamayacağını belirtmiştir. Buna ek olarak, üstün yetenekli çocukların eğitimini destekleyen araştırmacılar da eğitim programlarının belirlenmesinde ilgi kavramının merkezde yer alması gerektiğini savunmuşlardır (Gallagher, 1985; Maker, 1982; Parke, 1989; Passow, 1982; Renzulli, 1994). Ayrıca Good ve Brophy (1987) de tüm öğrencilere okul ortamında ilgilerini keşfederek geliştirmek için firsat sunulması gerektiğini belirtmiştir. Hootstein (1994) öğrencileri motive etmek için öğrenmenin, öğrencilerin ihtiyaç, ilgi, endişe ve tecrübeleri ile ilişkilendirilmesini ve onların ilgi duydukları konular üzerine çalışmalarının teşvik edilmesini önermiştir. Kısacası, ilgi motivasyona, motivasyon da öğrenmeye bağlıdır ve bunun bir sonucu olarak ilgilerin incelenmesi ve ölçülmesinin öğretim ve öğrenmenin iyileştirilmesi için önemli öngörüler ve fikirler sağlayacağı ortadadır (Deci \& Ryan, 1985; Schiefele, 1991; Tobias, 1994).

Öğrenme ve motivasyona etki eden bir başka faktör olan sınırları zorlama (challenge) kavramının değerlendirilmesinde, Vygotsky'nin (1962) çocukların kendi becerilerinin az da olsa ötesinde olan etkinlikleri tercih etmeleri ve böylece de zihinsel gelişimin zor görevler gerektirdiği gözlemi önemli bir yer taşımaktadır. Öğrencilerin sınırlarını zorlayıcı, daha iyiye ulaşmaları için onları teşvik edici görevlere ve eğitsel etkinliklere duyulan ihtiyaç ortadadır. Öğrenciler için onların potansiyellerini ortaya çıkartıcı ve onların sınırlarını zorlayan bir eğitim programı oluşturulmasının öğrenme fırsatlarını daha üst seviye getireceği söylenebilir. Buna rağmen, birçok sınıfta öğrenciler için sınırlarını zorlamalarını, daha iyiyi yapmalarını teşvik eden etkinliklere rastlanmamaktadır ve bu da sıkılmış ve bıkmış, bunun sonucunda da potansiyellerine ulaşamayan öğrenciler yaratmaktadır (Archambault vd. 1993; Feldhusen \& Kroll, 1991; Goodlad, 1984; Reis vd., 1993; Westberg, Archambault, Dobyns \& Salvin, 1993). Eccles ve Midgiey (1989) öğretmenlere gençlerin akademik performansları ile ilgili yüksek beklentilere sahip olmalarını ve onları buna uygun şekilde zorlamalarını önermiştir. Ayrıca Clifford (1990) da başarının motivasyon ile ilgili olduğunu ve öğrencilerin sınırlarını zorlayıcı görevlerin varlığı ile motivasyonun ve başarının elde edilebileceğini belirtmiştir. Üstün yetenekliler alanındaki araştırmacılar ve program geliştirme uzmanları eğitimcilerin pek çok farklı yöntem kullanarak öğrencilerin yeteneklerinin sınırlarını zorlayacak ve bu yolla onları geliştirecek çeşitli içerikler yaratabileceklerini belirtmişlerdir. Bu yollardan bazıları; etkinlikler sırasında karmaşık içeriklere odaklanmak; etkinliklere ileri düşünme becerilerini entegre etmek; etkinlikler sırasında orjinal yöntemler kullanıp gerçek durumlar ve problemler için ürünler ve 
yöntemler geliştirmek ve son olarak da müfredatı sıkıştırmak, hızlandırmak ve farklılaştırmaktır. (Bloom, 1985; Reis vd., 1993; Renzulli, 1994; Schlichter, 1986; Tomlinson, 1992, 1999; Treffinger, 1986). Doğru zorluğa sahip bir müfredat ve etkili öğretim yöntemleri geliştirerek, eğitimciler tüm başarı seviyelerindeki öğrencilere yüksek kalitede bir eğitim verebilirler (Bloom, 1985; Shore, Cornell, Robinson \& Ward, 1991; Vygotsky, 1962).

Renzulli (1994), öğrencilerin derinden ilgi duydukları ve kendileri yapmayı seçtikleri projeler ile ilgili çalıştıklarında daha anlamlı öğrenmeler gerçekleştiğini belirtmiştir. Çeşitli araştırmacılar (Bloom, 1985; Dewey, 1913, 1916; Gardner, 1991; Goodlad, 1984; Renzulli \& Reis, 1997; Shore vd., 1991; Wang \& Lindvall, 1984) kendi eğitimleri konusunda öğrencilere seçenek vermenin öğrenmeyi teşvik eden motivasyonel bir araç olduğunu belirlemişlerdir. Pintrich ve DeGrot (1990) ortaokul öğrencileri için kendi kontrollerinde olan ve seçim olanakları içeren öğrenmenin daha yüksek etkililik ve akademik performansa yol açtığını bulmuşlardır. Buna ek olarak, Faske ve Grubb (1997) öğrencilerin, öğretmenlerinin öğrenci merkezli yöntemler kullandıklarını algıladıkları durumlarda başarıda, kendine yeterlik ve etkililikte pozitif etkiler görüldüğünü bulmuşlardır. Deci (1995) öğrencilerin kendi kendilerine yetebilmeleri yolunda onlara seçenekler sunulmasının önemine değinmiştir. Seçeneklerin varlı̆̆ unsurdur. Buna uyumlu olarak hem Deci (1995) hem de Glasser (1996) sınıf ortamında seçenekler sunmanın öğretmenlerin güçlerini öğrenciler ile paylaşmasını gerektirdiğini ve böylece de öğrencilerin kendi öğrenmelerini sahiplendiklerini ve bu doğrultuda kararlar almalarını sağladığını gözlemlemişlerdir. Benzer bir şekilde, Kerka (1994) hedefler, amaçlar, katılım şekli, içerik, yöntem ve değerlendirme üzerinde söz sahibi olmanın öz düzenleyici öğrenme için önemli olduğunu iddia etmiştir. Bandura (1997) da kendi amaçlarını belirlemesine izin verilen öğrencinin onlara ulaşmada da daha aktif olacağını net bir şekilde belirtmiştir. Birey tarafından belirlenen, serbestçe seçilen ve birey tarafından kontrol edilen öz düzenleyici davranışlar, sonuçta üstlenilen göreve karşı yüksek ilgi, yaratıcılık, bilişsel esneklik, olumlu duygular ve sebat sağlayacaktır (Betts \& Kercher, 1999; Deci \& Ryan, 1985). Kısaca, öğrencilere eğitim etkinlikleri sırasında seçim yapabilme şansı vermek ilgi, başarı ve sahiplik hissini artırmaya fayda sağlamaktadır.

Eğitsel etkinliklerden zevk alınmasının öğrenme sürecinde motive edici bir faktör olduğu gözardı edilemez. Lepper ve Chabay (1985) öğrencilerin kontrol duygularını artırmak, sınırlarını zorlayıcı etkinlikler sunmak, merak uyandırmak ve etkinliklerin sahip oldukları fonksiyonları ön plana çıkarmak gibi yollarla sınıfta motivasyonu artırmanın mümkün olduğunu söylemiştir. Bu yolla aynı zamanda öğrenmeyi hem eğlenceli hem de verimli yapmanın mümkün olduğundan bahsetmiştir. Ayrıca, diğer araştırmacılar da (Csikszentmihalyi, 1990; Dewey, 1916; Renzulli, 1994; Schiefele, 1991) etkili eğitim uygulamaları için çekici ve eğlenceli öğrenme tecrübeleri sunmanın gerekli olduğunu söylemişlerdir. Renzulli (1994) en iyi öğrenmenin çocukların yaptıklarından keyif aldıkları zaman gerçekleştiğini gözlemlemiştir. Buna ek olarak, yüksek yaratıcılığa sahip üretken kişilerin yaptıklarından zevk aldıkları zaman en yüksek performans seviyelerine ulaştıklarını da söylemiştir. Öğrenmenin keyifli ve ilgi çekici olması kavramına bağlı olarak, öğrencilerin öğretmekten zevk alan (Csikszentmihalyi \& McCormack, 1986) ve öğrettikleri konulara tutkuyla bağlı olan (Renzulli, 1988) öğretmenlerden daha verimli bir şekilde öğrenebildikleri düşüncesi de bulunmaktadır. Günlük sınıf etkinliklerinden zevk alınmasını sağlayacak öğeler dahil edildiğinde okulun hem öğrenciler hem de öğretmenler için daha iyi bir öğrenme ortamı haline gelmesi mümkün olacaktır.

Buraya kadar aktarılan bilgilerden de görüldüğü üzere, ilgi, konudan zevk alma, sınırları zorlama ve seçeneklerin olması gibi faktörler, hem öğrenme ortamının kalitesini hem de öğrenenin motivasyonunu artıran unsurlardır. Gentry ve Gable (2001) Sınıf Etkinliklerim Ölçeği'nde tüm bu faktörleri bir arada ölçebilecek bir araç ortaya koymuştur. Türkiyede'ki alan yazın incelendiğinde bu dört önemli boyutu birden ölçen bir ölçme aracına rastlanmamıştır. Yurtdışı alan yazında ölçeğin geliştirildiği zamandan beri öğrenme ortamlarındaki bu dört farklı boyutu ölçmek amacıyla pek çok farklı araştırmada da kullanılmış olduğu görülmektedir (Aryan \& Shahrokhi, 2015; Gentry \& Gable, 2001; Gentry, Gable \& Rizza, 2002; Gentry, Gable \& Springer, 2000; Gentry, Rizza \& Gable, 2001; Gentry, Rizza \& Owen, 2002; Pereira, Peters \& Gentry, 2010; Yang, Gentry \& Choi, 2012). Gentry ve Gable (2001) tarafından Amerika'da geliştirilen bu ölçek, geliştirildiği kültürdeki farklı öğrenci 
gruplarında da uygulanmış (Pereira, Peters \& Gentry, 2010), aynı zamanda Güney Kore (Yang, Gentry \& Choi, 2012) kültürüne uyarlama çalışması yapılmış, Arapça (Aryan \& Shahrokhi, 2015) ve Çince'ye (Yang \& Gentry, 2011) ise çevirisi gerçekleştirilmiştir. Oldukça yaygın bir kullanım alanına sahip olan bu ölçeğin alanyazındaki önemli bir boşluğu dolduracağı ve çeşitli disiplinlerde araştırmalar yürütmekte olan pek çok araştırmacının kullanacağı düşünülmektedir.

\section{Araştırmanın Amacı}

Bu çalışmada öğrencilerin sınıf etkinliklerine yönelik ilgi duyma, etkinlik konularından zevk alma, etkinliğin konusuyla ilgili seçim yapabilme ve etkinlik sırasında sınırlarını zorlamalarına ilişkin algılarını ölçen "Sınıf Etkinliklerim Ölçeği”"nin geçerlik ve güvenirlik çalışmasının yapılarak Türk kültürüne uyarlanması amaçlanmıştır.

\section{YÖNTEM}

\section{Araştırmanın Modeli}

Araştırma tarama modelinde betimsel bir araştırmadır. Karasar (2016)'a göre, betimsel çalışmalar; olayların, objelerin, varlıkların, kurumların, grupların ve çeşitli alanların "ne" olduğunu betimlemeye, açıklamaya çalışan çalışmalardır.

\section{Çalışma Grubu}

Araştırmanın çalışma grubu, Ankara ili Mamak İlçe Milli Eğitim Müdürlüğü Büyük Elçi Nazım Belger İlkokulu ve Şehitlik Ortaokulu, Çankaya İlçe Milli Eğitim Müdürlüğü Rauf Orbay İlkokulu ve Rauf Orbay Ortaokulu, Ankara Üniversitesi Geliştirme Vakfi Özel İlkokulu ve Ankara Üniversitesi Geliştirme Vakfi Özel Ortaokulu'nda 2015-2016 eğitim-öğretim döneminde 3.,4., 5., 6.,7. ve 8. sınıflarında öğrenim gören ve çalışmaya katılmaya gönüllü 214 öğrenciden oluşmaktır. Çalışma grubunun betimsel özelliklerini içeren bilgiler Tablo 1'de yer almaktadır.

Tablo 1. Çalışmaya Katılan Öğrencilerin Betimsel Özelliklerinin Dağılımı

\begin{tabular}{llcc}
\hline Özellik & & $\mathrm{n}$ & Yüzde \\
\hline Cinsiyet & & & \\
& Kız & 108 & 50,5 \\
& Erkek & 106 & 49,5 \\
\hline Sinıf Düzeyi & & & \\
& 3 & 40 & 18,7 \\
& 4 & 38 & 17,8 \\
& 5 & 37 & 17,3 \\
& 6 & 32 & 15 \\
& 7 & 35 & 16,4 \\
& 8 & 32 & 15 \\
Toplam & & 214 & 100 \\
\hline
\end{tabular}

Tablo 1'e göre çalışmaya katılan öğrencilerin \%50,5'i k1z, \%49,5'i erkektir. Öğrencilerden yaş1 10 olanlar $(\% 22,4)$ ve 3. sınıfa devam edenler $(\% 18,7)$ diğer öğrenciler arasında en fazla orana sahip olan öğrenci grubudur. Çalışmaya katılan en yüksek sayıdaki öğrenci grubu Ankara Üniversitesi Geliştirme Vakfı İlkokulu ve Ortaokulu'ndandır. Öğrencilerin yaşları ve örneklemdeki yüzdeleri; 8 yaş $(\% 0,9), 9$ yaş $(12,6), 10$ yaş $(\% 22,4), 11$ yaş $(\% 15,4), 12$ yaş $(\% 15,4), 13$ yaş $(\% 18,2), 14$ yaş $(\% 13,6)$ ve 15 yaş $(\% 1,4)$ şeklindedir. Çalışmaya katılan öğrencilerin \% 30,8'i Büyük Elçi Nazım Belger İlkokulu ve Şehitlik Ortaokulu'ndan, \%32,2'si Rauf Orbay İlkokulu ve Rauf Orbay 
Ortaokulu'ndan ve \% 36,9 u Ankara Üniversitesi Geliştirme Vakfi Özel İlkokulu ve Ortaokulundan gelmektedir.

\section{Ölçeğin Deneme Uygulamasına İlişkin Çalışma Grubu ve Süreç}

Hazırlanan ölçeğin ilk deneme uygulaması, Çankaya İlçe Milli Eğitim Müdürlüğü Hamdullah Suphi İlkokulu'nda öğrenim gören 30 öğrenci ile yapılmış ve öğrenciler tarafindan net anlaşılmayan 3 madde tespit edilerek düzeltilmiştir. Ölçeğin deneme uygulamasında ayrıca sınıf öğretmenlerinden de ölçeğin çocukların gelişim düzeyine uygun olup olmadığı hakkında uzman görüşü alınmış, gelen uzman görüşleri doğrultusunda gerekli düzeltmeler yapılarak ölçeğin deneme formu revize edilerek uygulama formu hazırlanmış ve çalışma grubuna uygulanmıştır. Araştırma hakkında verilen ön bilgiden sonra gönüllü olan aile ve öğrenciler araştırmaya katılmıştır.

\section{Veri Toplama Araçlart}

\section{Sınıf Etkinliklerim Ölçeği (My Class Activities Survey)}

$\mathrm{Bu}$ ölçek Gentry ve Gable (2001) tarafından geliştirilmiştir. Ölçekte, üst düzey öğrenmelerin temelinde yatan alt boyutlar olan eğitsel etkinliğe ilgi duyma, etkinlik yapılan konudan zevk alma, konuyla ilgili seçim yapabilme ve etkinlik sırasında sınırlarını zorlama boyutlarının sınıftaki etkinlikler sırasında ne kadar gerçekleştiğine ilişkin öğrenci algıları ölçülmeye çalışılmaktadır. Ölçek 3.-8. sınıf arasındaki öğrenciler için geliştirilmiş bir ölçektir ve orjinali 31 maddeden oluşmaktadır. Yukarıda da belirtildiği gibi eğitsel etkinliğe ilişkin İlgi Duyma, Seçim Yapabilme, Sınırlarını Zorlama ve Konudan Zevk Alma olmak üzere ölçeğin toplam 4 alt boyutu bulunmaktadır ve bunlar ölçeği geliştirenler tarafından aşağıdaki gibi tanımlanmışlardır (Gentry \& Gable, 2001):

1. İlgi Duyma (Interest): Bu alt boyut öğrencinin belli konulara, içeriğe veya etkinliklere karşı olumlu duygular beslemesi, onlara ilgi duyması ve onları tercih etmesi olarak açıklanmaktadır.

2. Seçim Yapabilme (Choice): Bu alt boyut, öğrenciye öğrenmesi sırasında eğitim ortamında ona sunulanlar arasından seçim yapabilme gücünü ve şansını vererek kendi öğrenmelerini kendisinin yönlendirebilmesini sağlaması olarak açıklanmıştır.

3. Sınırlarını Zorlama (Challenge) Öğrencinin zihnini meşgul etmesi ve bu sırada her zaman harcadığından farklı ve daha üst düzeyde bir zihinsel çabayı aynı zamanda bundan keyif alarak harcaması kastedilmektedir.

4. Konudan Zevk Alma (Enjoyment): Öğrencinin öğrenme ortamında ilgilendiği her ne ise bundan zevk alması ve tatmin olması kastedilmektedir (Gentry \& Gable, 2001).

Ölçekte Likert tipi cevap formatı kullanılmıştır. Bu format "Hiçbir Zaman" (1) ile "Her Zaman” (5) arasındadır. Öğrenciler ölçekte yer alan 31 maddenin her birinin sınıf etkinlikleri sırasında ne kadar yer aldığını düşünüyorlarsa ona göre derece vererek değerlendirirler. Ölçeğin puanlarının tüm alt boyutlarda yüksek çıkması öğrencinin sınıfındaki etkinlikleri yüksek oranda ilgi çekici, seçim yapmaya müsait, zihinsel olarak zorlayıcı ve zevkli olarak algıladığı anlamına gelmektedir. Düşük skorlar da tahmin edileceği üzere bu alt boyutların öğrenciler tarafından sınıf etkinlikleriyle ilgili düşük düzeyde algılandığını göstermektedir. Örneğin "Zihinsel Zorlanma" alt boyutunun ortalamasından alınan 4,5 ortalama, öğrencilerin sınıftaki etkinlikleri sıklıkla ve olumlu anlamda zihinsel olarak zorlayıcı, fazladan çaba sarf ettirici fakat cazip/çekici şekilde algıladıkları anlamına gelecektir. Öte taraftan "Zevk Alma" boyutundan ortalama olarak 1 alınmış olması o sınıftaki etkinliklerin öğrenciler tarafından keyifli veya tatmin edici olarak algılanmadığını gösterecektir (Gentry \& Gable, 2001). Ölçeğin geliştirme çalışmasında Doğrulayıcı Faktör analizi yapılmış Uyum iyiliği değerlerinin Tucker-Lewis için 0,92 ve RMSEA için 0,04 olduğu görülmüştür. Ayrıca boyutlar arası korelasyon değerleri 0,36 ile 0,77 arasında elde edilmiştir. Ölçeğin güvenirlik çalışması olarak elde edilen Cronbach alfa katsayısı İlgi Duyma, 0,89; Sınırları Zorlama, 0,78; Seçim Yapabilme, 0,75; Keyif Alma, 0,92’dır (Gentry \& Gable, 2001). 


\section{Süreç}

Ölçeğin çeviri çalışmalarının gerçekleştirilebilmesi için öncelikle ölçeği geliştiren Amerikalı araştırmacılardan yazııı izin alınmıştır. Sonrasında uyarlama ile ilgili uygulamaların yapılabilmesi için TED Üniversitesi Etik Kurulu'ndan, Milli Eğitim Bakanlığı'ndan ve Ankara Üniversitesi Geliştirme Vakfı Okulları'ndan yazılı izin alınmıştır. Daha sonra çeviri aşamasıyla ilgili aşağıda aktarılan adımlara geçilmiştir.

\section{Çeviri Aşamasına İlişkin Yapılan Çalışmalar}

Ölçeğin ülkemize uyarlamasını yapmak üzere ilk olarak Sınıf Etkinliklerim Ölçeği'nin Türkçe’ye çevirisi için bir ön çalışma yapılmıştır. Bu ön çalışma çeviri ve geri-çeviri olmak üzere iki aşamadan oluşmuştur. İlk aşamada ölçeğin maddeleri İngilizce'den Türkçe'ye dört uzman (Üstün yetenekliler alanında yurtdışında eğitim almış iki uzman ve yabancı diller eğitimi alanında uzman olup üstün yetenekliler konusunda doktorası bulunan iki uzman) tarafından çevrilmiştir. Çeviride daha iyi sonuç alınması için çeviri yapacak akademisyenler panel şeklinde toplanarak beyin firtınası yöntemiyle maddeler üzerinde çalışmışlardır. Daha sonra bu taslak çeviri örnekleri araştırmacılar tarafından değerlendirmeye alınmıştır. Değerlendirmede her bir ölçek maddesi için önerilen alternatifler arasından en uygun olanının seçilmesi veya eğer uygunsa yeni bir alternatif önerilmesi istenmiştir. $\mathrm{Bu}$ işlem sonucunda uzmanlardan ortak onay alan maddelerden oluşan Türkçe formu oluşturmuştur. Sonraki aşama olan geri-çeviri aşamasında, elde edilen ölçek maddeleri farklı üç uzman tarafindan yeniden İngilizce'ye çevrilmiştir. Bu sonuçla elde edilen maddeler üzerinde gerekli düzenlemeler yapılarak ölçeğin deneme formu oluşturulmuştur (Deniz, 2007).

\section{Ölçeğin Orijinal Formunun Metninde Yapılan Değişikliklere İlişskin Çalışmalar}

Ölçeğin as1l formunda 3. madde olan " What 1 do in my class gives me interesting and new ideas." ifadesi deneme uygulamasının Türkçe formunda iki madde olarak bölünmüş 3. (Sinıfta yaptıklarım ilgimi çeker.) ve 4. (Sinıfta yaptıklarım bana yeni fikirler verir.) madde olarak iki madde olmuştur. $\mathrm{Bu}$ değişimin nedeni ölçeğin asıl formunda iki ayrı tutumun aynı ifade içinde verilmiş olmasından kaynaklanmaktadır. Ölçeğin asıl formunda 13. madde "My work can make a difference" ifadesi Türkçe karş1lığ1 "Yaptığım çalışmalar günlük yaşama katkı sağlar." şeklini almıştır. Araştırmaya katılacak çocukların gelişim özellikleri ve ülkemizde fark yaratmanın çeşitli algılara neden olacağ düşünülerek bu değişiklik yapılmıştır. Ölçeğin asıl formunda 17. madde " This class is difficult" ifadesi Türkçe karşılığ 1 "Sinıf etkinliklerimiz yeteneklerimizi zorlamamızı sağlar." şeklini almıştır. Araştırmaya katılan çocukların gelişim özellikleri dikkate alındığında "Bu sınıf zordur" ifadesinin genel ve belirsiz olması dolayısıyla bu değişiklik yapılmıştır. Ölçeğin deneme uygulamasında 6 sınıf öğretmeninden ölçeğin çocukların gelişim düzeyine uygun olup olmadığı hakkında uzman görüşü alınmıştır.

\section{Verilerin Analizi}

Verilerin analizinde, SPSS 23 ve LISREL 8.7 programlarından faydalanılmıştır. Ölçeğin geçerlik çalışmasında z puanları alınmış 5 kişinin z puanı 2,5'ten büyük olduğu için (Uç değer belirlemede farklı yöntemler olmakla birlikte 2,5 z puanı tüm grubun \%99'unu kapsadığ 1 için uç değerler çıkartılmıştır.) uç değer kabul edildiğinden 4 kişi de tamamına olumlu yanıt verdiğinden datalardan silinmiş, analizler 3. sınıf ile 8. sınıf arası toplam 214 öğrenci üzerinden yapılmıştır. Öncelikle orijinal kültürdeki yapının doğrulanıp doğrulanmadığını belirlemek için Doğrulayıcı Faktör Analizi (DFA) yapılmış ve madde toplam korelasyonları hesaplanmıştır. Daha sonra alt boyutlar için 
Deniz, K. Z., Saranlı, A. G. / Sınıf Etkinliklerim Ölçeği’nin (SEÖ) Türk Kültürüne Uyarlanması: Geçerlik ve Güvenirlik Çalışması

Cronbach alfa güvenirlik katsayısı hesaplanmıştır. Bir başka geçerlik kanıtı olarak ölçeğin alt boyutları arasındaki korelasyon katsayıları Pearson korelasyon katsayısı ile hesaplanmıştır.

\section{BULGULAR}

Sınıf Etkinliklerim Ölçeği'nin Türk kültürüne uyarlama çalışmasında geçerlik kanıtı olarak elde edilen DFA, madde-toplam korelasyonları, boyutlar arası korelasyon ve güvenirlik kanıtı olarak elde edilen Cronbach alfa katsayısına ilişkin bulgular bu bölümde ye almaktadır. Öncelikle orijinal ölçekteki madde ve boyutlarla uyumlu olarak DFA yapılmıştır. DFA'ya yönelik elde edilen path diyagramı Şekil l'de yer almaktadır.

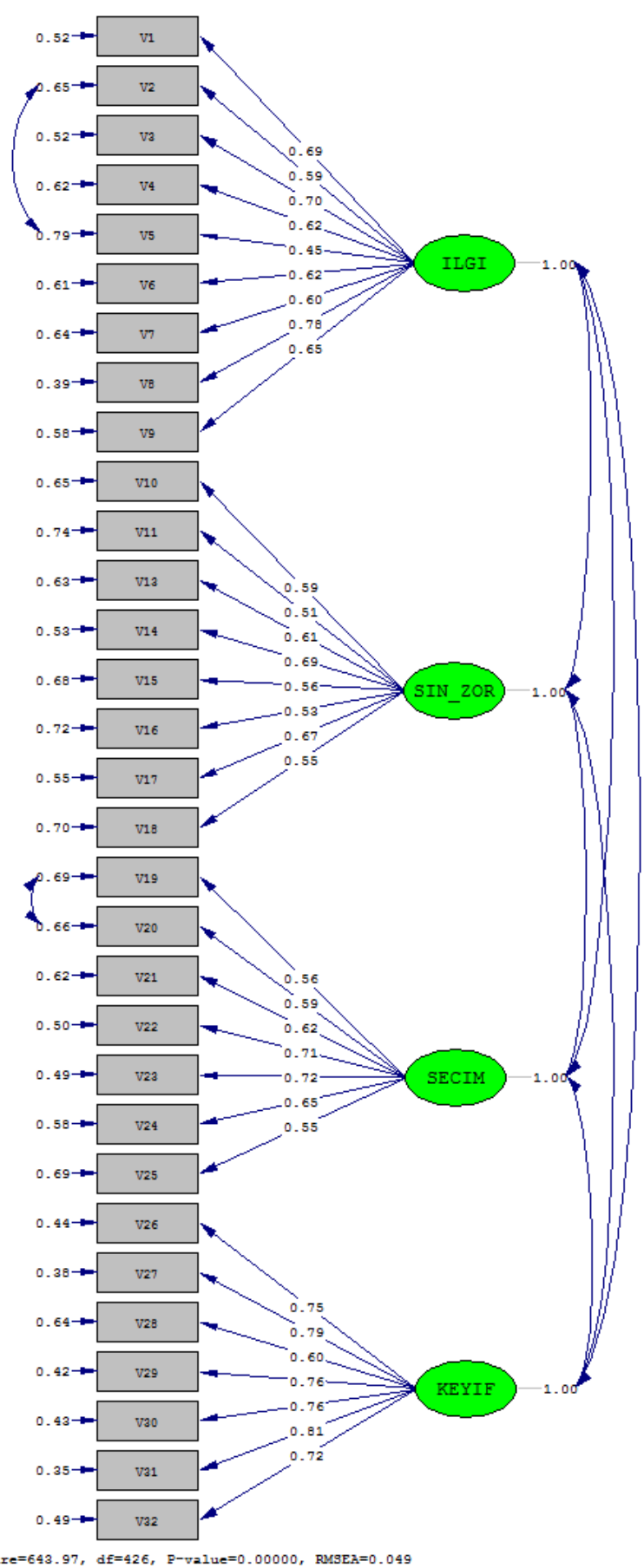


Şekil 1. Sınıf Etkinliklerim Ölçeği DFA Bulguları

Şekil 1 incelendiğinde maddelerle boyutları arasındaki yol katsayılarının İlgi için 0,45-0,78; Sınırları Zorlama için 0,51-0,67; Seçim Yapabilme için 0,55-0,72 ve Keyif Alma için 0,60-0,81 arasında değiştiği gözlenmiştir. Bu maddeler en az 0,20 varyans açıklamaktadırlar. Açıkladıkları varyans ve ilişki değerlerinin orta ve üzeri olması nedeniyle bu değerlerin yeterli olduğu kabul edilmiştir (Büyüköztürk, 2016). Şekil 1'de görüldüğg̈ gibi İlgi boyutunda yer alan ikinci ve beşinci madde ile Seçim Yapabilme boyutunda yer alan 19. ve 20. maddelerin hata varyansları ki-kare değerini önemli ölçüde düşürdüğü için eşitlenmiştir. Bu maddelerin içerikleri incelendiğinde ikinci madde "Sınıfta ilgimi çeken konular üzerinde çalışma fırsatım olur.", beşinci madde ise "Sınıfta ilgi çekici konular üzerinde çalışırım.” şeklindedir. Her iki madde de ilgi çekici konu üzerinde çalışmayla ilgili birbirini tamamlayan ve paralel görünen ifadelerdir. Bunun yanısıra 19. madde "Sınıf etkinliklerimizde grupla çalışıp çalışmayacağımı kendim seçebilirim." ve 20. madde "Sınıf etkinliklerimizde tek başıma çalışıp çalışmayacağımı kendim seçebilirim." şeklinde olup bu iki madde de birbirini tamamlayıcı niteliktedir. Dolayısıyla DFA'da yapılan hata varyanslarının eşitlenmesi işleminin yerinde olduğu sonucuna varılabilir.

Sınıf Etkinliklerim Ölçeği’nin DFA sonuçlarının uyumuna ilişkin istatistikler ise Tablo 2'de verilmiştir.

Tablo 2. Sınıf Etkinliklerim Ölçeği İçin Uyum İyiliği Değerleri

\begin{tabular}{lllllllll}
\hline Ki-Kare & sd & Ki-Kare /sd & CFI & NFI & GFI & IFI & NFI & RMSEA \\
\hline 643,97 & 426 & 1,51 & 0,98 & 0,94 & 0,84 & 0,98 & 0,94 & 0,049 \\
\hline
\end{tabular}

Tablo 2 incelendiğinde ki-kare değerinin serbestlik derecesine oranı iki katın altında olduğu görülmektedir. RMSEA değeri incelendiğinde 0,049 olduğu görülmektedir. CFI, AGFI ve NFI değerleri incelendiğinde tüm alt boyutlarda bütün bu değerlerin 0,90 'ın üzerinde olduğu görülmektedir. GFI değerinin $(0,84)$ 0,80'in üzerinde olduğu görülmektedir. Byrne (1998)'ye göre bu uyum indeksleri kabul edilebilir uyumu göstermektedir. Sınıf Etkinliklerim Ölçeği'nin Düzeltilmiş Madde Toplam Korelasyonu ve Cronbach Alfa Değerleri Tablo 3’te yer almaktadır.

Tablo 3. Sınıf Etkinliklerim Ölçeğinin Düzeltilmiş Madde Toplam Korelasyonu ve Cronbach Alfa Değerleri

\begin{tabular}{cccc}
\hline $\mathrm{n}=214$ & $\begin{array}{c}\text { Ölçek } \\
\text { Madde No }\end{array}$ & $\begin{array}{c}\text { Nihai Ölçek } \\
\text { Madde No }\end{array}$ & $\begin{array}{c}\text { Düzeltilmiş Madde } \\
\text { Toplam Kolerasyonu }\end{array}$ \\
\hline \multirow{3}{*}{ İlgi Duyma } & 1 & 1 & 0,64 \\
& 2 & 2 & 0,59 \\
& 3 & 3 & 0,61 \\
& 4 & 4 & 0,58 \\
& 5 & 5 & 0,47 \\
& 6 & 6 & 0,56 \\
& 7 & 7 & 0,50 \\
Sinırlar1 Zorlama & 8 & 8 & 0,72 \\
& 9 & 9 & 0,57 \\
& 10 & 10 & 0,59 \\
& 11 & 12 & 0,44 \\
& 13 & 13 & 0,59 \\
& 14 & 14 & 0,56 \\
& 16 & 15 & 0,51 \\
& 17 & 16 & 0,52 \\
& 18 & 17 & 0,52 \\
& & & 0,55
\end{tabular}


Deniz, K. Z., Saranlı, A. G. / Sınıf Etkinliklerim Ölçeği’nin (SEÖ) Türk Kültürüne Uyarlanması: Geçerlik ve Güvenirlik Çalışması

\begin{tabular}{llll} 
& 19 & 18 & 0,58 \\
20 & 19 & 0,60 \\
21 & 20 & 0,57 \\
22 & 21 & 0,61 \\
23 & 22 & 0,58 \\
24 & 23 & 0,57 \\
25 & 24 & 0,48 \\
26 & 25 & 0,69 \\
27 & 26 & 0,74 \\
Keyif Alma & 28 & 27 & 0,56 \\
& 29 & 28 & 0,70 \\
& 30 & 29 & 0,71 \\
31 & 30 & 0,76 \\
32 & 31 & 0,67 \\
\hline \multirow{3}{*}{ Cronbach Alfa } & Sinirlari Zorlama:0,82 & & \\
& Seçim Yapabilme: 0,83 & & \\
\hline
\end{tabular}

Tablo 3 incelendiğinde, ölçeğin iç tutarlılığı için hesaplanan düzeltilmiş madde toplam korelasyonları İlgi Duyma için 0,47-0,72, Sınırları Zorlama için 0,44-0,59, Seçim Yapabilme için 0,48-0,61 ve Keyif Alma için 0,56-0,76 aralığındadır. Gentry ve Gable (2001)'nin ölçeği geliştirdikleri çalışmalarında düzeltilmiş madde toplam korelasyonları İlgi Duyma için 0,61-0,74, Sınırları Zorlama için 0,32-0,64, Seçim Yapabilme için 0,28 - 0,54 ve Keyif Alma için 0,68-0,81 aralığındadır.

Sınıf Etkinliklerim Ölçeği'nin alt boyutlarına göre Cronbach alfa katsayıları, İlgi Duyma için 0,86; Sınırları Zorlama için 0,82; Seçim Yapabilme için 0,83 ve Keyif Alma için 0,90 olarak kestirilmiştir. Buna göre ölçek alt boyutları kabul edilebilir derecede güvenilirdir. Gentry ve Gable (2001)'nin ölçeği geliştirdikleri çalışmalarında, Sınıf Etkinliklerim Ölçeği'nin alt boyutlarının Cronbach alfa katsayısı (İlgi Duyma, 0,89; Sınırları Zorlama, 0,78; Seçim Yapabilme, 0,75; Keyif Alma, 0,92) en düşük 0,75 ve en yüksek 0,92 aralığında olduğunu belirtmişlerdir. Çalışma bulguları Gentry ve Gable (2001)'nin çalışma bulguları ile benzerlik göstermektedir. Sınıf Etkinliklerim Ölçeği'nde yer alan boyutlar arası korelasyonlar Tablo 4'te verilmiştir.

Tablo 4. Sınıf Etkinliklerim Ölçeğinin Alt Boyutları arasındaki Pearson Korelasyon Katsayıları

\begin{tabular}{lcccc}
\hline & $\mathrm{n}=214$ & İlgi Duyma & Sinırları Zorlama & Seçim Yapabilme \\
\hline \multirow{2}{*}{ Sinırları Zorlama } & Pearson K.K. & $0,77^{* *}$ & & \\
\multirow{2}{*}{ Seçim Yapabilme } & $\mathrm{p}$ & 0,000 & & \\
& Pearson K.K. & $0,45^{* *}$ & $0,50^{* *}$ & \\
\multirow{2}{*}{ Keyif Alma } & $\mathrm{p}$ & 0,000 & 0,000 & $0,36^{* *}$ \\
& Pearson K.K. & $0,72^{* *}$ & $0,70^{* *}$ & 0,000 \\
\hline
\end{tabular}

Tablo 3 incelendiğinde, Sınıf Etkinliklerim Ölçeği'nin İlgi Duyma alt boyutu ile Sınırları Zorlama, Keyif Alma, Seçim Yapabilme alt boyut puanları arasında pozitif yönde anlamlı düzeyde korelasyonlar olduğu görülmektedir $(\mathrm{p}<0,01)$. İlgi Duyma alt boyutu ile pozitif en yüksek ilişki gösteren alt boyutun Sınırları Zorlama alt boyutu olduğu $(0,77, \mathrm{p}<0,01$; ölçeğin orjinal formunun geliştirme çalışmasında $0,50, \mathrm{p}<0,01$ elde edilmiştir (Gentry ve Gable, 2001); en düşük ilişsinin Seçim Yapabilme alt boyutuyla olduğu $(0,45, \quad \mathrm{p}<0,01$ Ölçeğin orjinal formunungeliştirme çalışmasında 0,39, $\mathrm{p}<0,01$ elde edilmiştir (Gentry ve Gable, 2001)) göze çarpmaktadır. Sınırları Zorlama alt boyutu ile Seçim Yapabilme $(0,50, p<0,01$; Ölçeğin orjinal formunungeliştirme çalışmasında 0,39, p<0,01 elde edilmiştir (Gentry ve Gable, 2001)) ve Keyif Alma $(0,70, p<0,01$; 
Ölçeğin orjinal formunun geliştirme çalışmasında $0,40, p<0,01$ elde edilmiştir (Gentry ve Gable, 2001) alt boyut puanları arasında anlamlı düzeyde korelasyonlar olduğu görülmektedir. Seçim Yapabilme alt boyutu ile Keyif Alma $(0,36, \quad \mathrm{p}<0,01$; Ölçeğin orjinal formunun geliştirme çalışmasında 0,49, p<0,01 elde edilmiştir (Gentry ve Gable, 2001) alt boyut puanları arasında anlamlı düzeyde korelasyonlar olduğu görülmektedir. Büyüköztürk (2016)'e göre, korelasyon değerleri düşük $(0,00-0,29)$, orta $(0,30-0,69)$ ve yüksek $(0,70-1,00)$ olarak sinıflandırabilir. Buna göre, Sınıf Etkinliklerim Ölçeği'nde yer alan boyutlar arası korelasyonların orta ve yüksek düzeyde pozitif yönde olduğu görülmektedir. Çalışma bulguları Gentry ve Gable (2001)'nin çalışma bulguları ile benzerlik göstermektedir.

\section{SONUÇLAR ve TARTIŞMA}

$\mathrm{Bu}$ araştırma kapsamında Gentry ve Gable (2001) tarafından Amerika Birleşik Devletleri'nde geliştirilmiş olan Sınıf Etkinliklerim Ölçeği’nin uyarlama çalışması gerçekleştirilmiş ve ölçeğin Türk kültüründe kullanımı için gerekli olan geçerlik ve güvenirlik kanıtları ortaya konmuştur. Geçerlik çalışması kapsamında öncelikle DFA yapılmıştır. DFA sonucunda ölçeğin Türk kültüründe orijinal ölçekteki faktör yapısıyla aynı şekilde kullanılabileceği sonucuna ulaşılmıştır. DFA için elde edilen uyum iyiliği değerleri dört faktörlü yapının kabul edilebilir bir uyum gösterdiği sonucunu ortaya koymuştur.

Ilgili alan yazında ölçeğin farklı kültürlere ve aynı kültür içindeki farklı öğrenci gruplarına uygulanmış olduğu daha önce de belirtilmişti. Örneğin Pereira vd. (2010) tarafından yapılan çalışmada sınıf düzeyleri üç ila sekizinci sınıf arasında değişen 826 üstün yetenekli çocuk üzerinde ölçek uygulanmıştır. Amerikan kültüründeki üstün yetenekli çocuk grubunun örneklem olarak alındığıbu çalışmada, 16 ve 17. maddeler önemli bir modifikasyon verdiği için bu maddeler ölçekten çıkartılmıştır. Ölçeğin dört faktörlü yapısı bu çalışmada da doğrulanmıştır. Yang vd. (2012)’nin ölçeği Güney Kore kültürüne uyarlama çalışmasında 3. Sınıftan 6. Sınıfa kadar Güney Korenin dört farklı şehrinden seçilmiş toplam 564 öğrenci örnekleme dahil edilmiştir. Bu çalışmada da 17. madde ölçekten çıkartılarak dört faktörlü yapı doğrulanmıştır. Benzer şekilde bu çalışmada da toplamda dört maddenin hata varyansları eşitlenerek model doğrulanmıştır. Aryan ve Shahrokhi (2015) tarafından yapılan çalışmada ölçek İran'da uygulanmış ancak uyarlama çalışması gerçekleştirilmemiştir. Uyarlamak yerine İngilizce olan orijinal ölçek İngilizce öğrenen grup üzerinde kullanılmıştır. Belirlenen faktör yapıları dahilinde her maddenin ilgili faktör yapısıyla olan korelasyonu maddetoplam korelasyonları ile hesaplanmış ve bu değerlerin de DFA sonucunda elde edilen yapının uygunluğunu gösterir şekilde olduğu görülmüsstür. Bununla birlikte boyutlar arası korelasyon değerleri incelendiğinde boyutları birbirinden yeterince ayrışmış bir ölçek için beklenenden yüksek değerler verdiği sonucu da ortaya çıkmıştır. Ancak Gentry ve Gable (2001)'ın orijinal ölçek geliş̧irme çalışmasında da boyutlar arası korelasyon 0,39 ile 0,76 arasında değer almıştır. Yang vd. (2012)'nin Güney Kore kültürü’ne uyarlama çalışmalarında ise 0,67 ile 0,88 arasında korelasyon değerleri elde edilmiştir. Boyutlar arası korelasyon değerlerinin yüksek olmasının nedeni, tüm maddelerin öğrencinin sınıf etkinlikleri ile ilgili olmasından kaynaklı olabileceği şeklinde açıklanabilir. Ölçeğin güvenirlik kanıtı olarak elde edilen Cronbach alfa değerleri de yeterli düzeydedir. Yang vd. (2012)'nin çalışmasında, bu çalışmaya parallel olarak, Cronbach alfa değerleri 0,74 ile 0,93 arasında elde edilmiştir. Sonuç olarak; Sınıf Aktivitelerim Ölçeği'nin Türk kültürüne uyarlaması sonucunda ölçeğin 32 maddeden ve dört boyuttan oluştuğu görülmüştür. Sınıf Etkinliklerim Ölçeği ile ölçülen boyutlar eğitim alanındaki pek çok teori ve pratikten güç almaktadır. Ayrıca ilgili boyutlar öğrenci motivasyonu ve öğrenme ile doğrudan ilgilidir. Sınıf Etkinliklerim Ölçeği kullanılarak, ilkokul ve ortaokul öğrencilerinin sınıflarındaki aktiviteleri nasıl algıladıkları değerlendirilebilir. $\mathrm{Bu}$ bilgiler sayesinde pratik anlamda eğitimciler gerçekleştirdikleri eğitsel etkinliklerin öğrenciler tarafından nasıl algılandığını, onları motive edecek düzeyde ilgi çekici, zevkli, seçenekli ve sınır zorlayıcı olup olmadığını görebilirler. Ölçeğin sonuçlarına göre eğitim ortamları ve etkinlikleri için amaçlar oluşturabilir ve önemli görülen alanlarda geliştirme planları oluşturabilirler. $\mathrm{Bu}$ konularda çalışan araştırmacılar Sınıf Etkinliklerim Ölçeği’ni, yapılan bir müdahalenin öğrencilerin okula karşı olan tavırlarında bir gelişmeye yol açıp açmadığını veya 
öğrenci tavırları ile başarı seviyeleri arasında bir bağlantı olup olmadığını ölçmek ve anlamak amacıyla kullanabilirler. Ayrıca değişik öğrenci grupları arasında okulda gerçekleştirilen etkinliklere yönelik düşünceler ile ilgili bir fark olup olmadığını veya diğer birçok araştırma sorusunu değerlendirmek için kullanabilirler. Örneğin ölçek normal gelişim gösteren öğrenciler dışında üstün yetenekli çocuklar veya özel gereksinimli diğer öğrenci gruplarına uygulanarak farklı öğrenci gruplarının okuldaki sınıf etkinliklerine ilişkin görüşleri incelenebilecektir. Öğrencilerin sınıf etkinliklerini değerlendirmelerinin incelenmesi hem araştırmacıların hem de eğitimcilerin etkili öğretim için kullanılabilecek yöntemleri incelemeleri ve oluşturmaları için yardımcı olacaktır. Bundan başka ölçeğin yaygın olarak kullanılamsı ülke genelinde eğitim programında gerçekleş̧irilebilecek değişiklik ve yeniliklerin hangi alanlarda olması gerektiği konusunda Milli Eğitim Bakanlığı yetkililerine ve bu konularda politika yapan kişilere 1şık tutabilecektir. Diğer çalışmalarda test tekrar test gibi farklı bir güvenirlik kanıtının elde edilmesi de uyarlanmış olan bu ölçeğe katkı sağlayacaktır. Bu çalışmada bulunan bazı sınırlılıklara değinmek gereklidir. Öncelikle uyarlama çalışmasında kullanılan örneklem rastgele örnekleme ile seçilmemiştir. Örneklemdeki vakıf okulundan gelen öğrenci sayısının devlet okulu öğrenci sayısından fazla olması bir başka sinırlılığı oluşturmaktadır.

\section{KAYNAKÇA}

Archambault, E. X., Westberg, K., Brown, S. B., Hallmark, B. W., Emmons, C. L., \& Zhang, W. (1993). Regular classroom practices with gifted students: Results of a national survey of classroom teachers. Storrs, CT: National Research Center on the Gifted and Talented.

Aryan, E., \& Shahrokhi, M. (2015). Students' perceptions of class activities: An investigation into the role of gender and grade level. Mediterranean Journal of Social Sciences, 6(4), 19-26.

Bandura, A. (1997). Self efficacy. New York: W. H. Freeman.

Betts, G. T., \& Kercher, J. K. (1999). Autonomous learner model optimizing ability. Greeley, CO: Autonomous Learning Publications \& Specialists.

Bloom, B. S. (Ed.) (1985). Developing talent in young people. New York: Ballantine.

Büyüköztürk, Ş. (2016). Veri analizi el kitabı. Pegem Akademi.

Byrne, B. M. (1998). Structural equation modeling with LISREL, PIRELIS and SIMPLIS: Basic concepts, applications and programming. Mahwah, New Jersey: Lawrence Erlbaum Associates.

Csikszentmihalyi, M. (1990). Literacy and intrinsic motivation. Daedalus, 119, 115-140.

Csikszentmihalyi, M., \& McCormack, J. (1986). The influence of teachers. Phi Delta Kappan, 67(6), 415-419.

Clifford, M. (1990). Students need challenge, not easy success. Educational Leadership, 48, 22-26.

Deci, E. L. (1995). Why we do what we do: The dynamics of personal autonomy. New York: G. P. Putnam's Sons.

Deci, E. L., \& Ryan, R. M. (1985). Intrinsic motivation and self determination in human behavior. New York: Plenum.

Deniz, K. Z. (2007). Psikolojik ölçme aracı uyarlama, Ankara Üniversitesi Eğitim Bilimleri Fakültesi Dergisi, 40(1), 1-16.

Dewey, J. (1913). Interest and effort in education. New York: Houghton Mifflin.

Dewey, J. (1916). Democracy and education. New York: The Free Press.

Eccles, J. S., \& Midgley, C. (1989). Stage-environment fit: Developmentally appropriate classrooms for young adolescents. In C. Ames \& R. Ames (Eds.), Research on motivation in education: Vol. 3 Goals and cognitions (pp. 13-44). New York: Academic.

Faske, D., \& Grubb, D. J. (1997). Implications of the learner-centered battery for new teacher standards and teacher education reform in Kentucky. Paper presented at the Annual Meeting of the American Psychological Association, Chicago, IL.

Feldhusen, J. E, \& Kroll, M. D. (1991). Boredom or challenge for the academically talented in school. Gifted Education International, 7, 80-81.

Gallagher, J. J. (1985). Teaching the gifted child (3rd ed.). Boston: Allyn \& Bacon

Gardner, H. (1991). The unschooled mind: How children think and how schools should teach. New York: Basic Books.

Gentry, M. \& Gable, R. K. (2001). From the students' perspective - my class activities: An instrument for use in research and evaluation. Journal for the Education of the Gifted, 24, 322-343.

Gentry, M., Gable, R. K., \& Rizza M. K. (2002). Students' perceptions of classrooms activities: Are there grade level and gender differences? Journal of Educational Psychology, 94, 539-544. 
Gentry, M., Gable, R. K, \& Springer, P. (2000). Gifted and non-gifted middle school students: Are their attitudes toward school different as measured by the new affective instrument, my class activities? Journal for the Education of the Gifted, 24, 74-96.

Gentry, M., Rizza, M. G., \& Gable, R. K. (2001). Gifted students' perceptions of their class activities: Differences among rural, urban, and suburban student attitudes. Gifted Child Quarterly, 45, 115-129.

Gentry, M., Rizza, M. G., \& Owen, S. V. (2002). Examining perceptions of challenge and choice in classrooms: The relationship between teachers and their students and comparison between gifted students and other students. Gifted Child Quarterly, 46, 145-155.

Glasser, W. (1996). Then and now. The theory of choice. Learning, 25, 20-22.

Good, T. L., \& Brophy, J. E. (1987). Looking in classrooms (4th ed.). New York: Harper \& Row.

Goodlad, J. (1984). A place called school. New York: McGrawHill.

Hootstein, E. W. (1994). Motivating middle school students. Middle School Journal, 25(5), 31-35.

James, W. (1890). The principles of psychology. London: MacMillan.

Karasar, N. (2016). Bilimsel araştırma yöntemi. Nobel Akademi.

Kerka, S. (1994). Self directed learning myths and realities. (ERIC Document Reproduction Service No. ED 365818).

Lepper, M. R., \& Chabay, R. W. (1985). Intrinsic motivation and instruction: Conflicting views on the motivational processes in computer-based education. Educational Psychologist, 20, 217-230.

Middleton, J. A. (1995). A study on intrinsic motivation in the mathematics classroom: A personal constructs approach. Journal for Research in Mathematics Education, 26, 254-279.

Middleton, J. A., Littlefield, J. \& Lehrer, R. (1992). Gifted students' conceptions of academic fun: An examination of a critical construct for gifted education. Gifted Child Quarterly, 36, 38-44.

Matthews, M. S., \& McBee, M. T. (2007). School factors and the underachievement of gifted students in a talent search summer program. Gifted Child Quarterly, 51, 167-181.

Maker, C. J. (1982). Curriculum development for the gifted. Austin, TX: Pro-Ed.

Pereira, N., Peters, S. J., \& Gentry, M. (2010). The my class activities instrument as used in Saturday enrichment program evaluation. Journal for Advanced Academics, 21(4), 568-593.

Parke, B. (1989). Gifted students in regular classrooms. Boston: Allyn and Bacon.

Passow, A. H. (1982). The relationship between the regular curriculum and differentiated curricula for the gifted/talented. Selected proceedings of the First National Conference on Curricula for the Gifted/Talented. Ventura, CA: Ventura Superintendents of Schools Office.

Pintrich, P. R., \& DeGroot, E. V. (1990). Motivational and self-regulated learning components of classroom academic performance. Journal of Educational Psychology, 82(1), 33-40.

Reis, S. M., Westberg, K. L., Kulikowich, J., Caiilard, R., Hebert, T., Plucker, J., Purcell, J. H., Rogers, J. B., \& Smist, J. M. (1993). Why not let high ability students start school in January? The curricidum compacting study. Storrs, CT: National Research Center on the Gifted and Talented.

Renzulli, J. S. (1978). What makes giftedness? Reexamining a definition. Phi Delta Kappan, 60(3), 180-184, 261.

Renzulli, J. S. (1988). The multiple menu model for developing differentiated curriculum for the gifted and talented. Gifted Child Quarterly, 32(3), 298-309.

Renzulli, J. S. (1994). Schools for talent development: A comprehensive plan for total school improvement. Mansfield Center, CT: Creative Learning.

Renzulli, J. S., \& Reis, S. M. (1997). The schoolwide enrichment model: A how-to guide for educational excellence (2nd ed.). Mansfield Center, CT: Creative Learning.

Schiefele, U. (1991). Interests, learning and motivation. Educational Psychologist, 26(3-4), 299-323.

Schlichter, C. (1986). Talents unlimited: Applying the multiple talent approach to mainstream and gifted programs. In J. S. Renzulli (Ed.), Systems and models for developing programs for the gifted and talented (pp. 352-390). Mansfield Center, CT: Creative Learning.

Shore, B. M., Cornell, D. G., Robinson, A., \& Ward, V. S. (1991). Recommended practices in gifted education. New York: Teachers College.

Tobias, S. (1994). Interest, prior knowledge and learning. Review of Educational Research, 64(1), 37-54.

Tomlinson, C. A. (1992). Gifted education and the middle school movement: Two voices on teaching the academically talented. Journal for the Education of the Gifted, 15(3), 206-238.

Tomlinson, C. A. (1999). Differentiation of curriculum: A guide. Arlington, VA: ASCD.

Treffinger, D. (1986). Fostering effective independent learning through individualized programming. In J. S. Renzulli (Ed.), Systems and models for developing programs for the gifted and talented (pp. 429-460). Mansfield Center, CT: Creative Learning.

Vygotsky, L. S. (1962). Thought and language. Cambridge, MA: M.I.T. 
Wang, M. C., \& Lindvall, C. M. (1984). Individual differences in school learning environments: Theory, research and design. In E. W. Gordon (Ed.), Review of research in educational (pp. 161-225). Washington, DC: American Educational Research Association.

Ward, V. (1980). Differential education for the gifted. Ventura, CA: Ventura Superintendent of Schools Office.

Westberg, K. L., Archambauit, E. X., Dobyns, S. M., \& Salvin T. J. (1993). An observational study of instructional and curricular practices used with gifted and talented students in regular classrooms. Storrs, CT: The National Research Center on the Gifted and Talented.

Whitehead, A. N. (1929). The rhythm of education. In A. N. Whitehead (Ed.), The aims of education (pp. 4659). New York: MacMillian.

Yang, Y., \& Gentry, M. (2011). Gifted and general elementary students’ perceptions in China and the United States: A cross-national study. Manuscript submitted for publication.

Yang, Y., Gentry, M., \& Choi, Y. O. (2012). Gifted students’ perceptions of the regular classes and pull-out programs in South Korea. Journal of Advanced Academics, 23(3), 270-287.

\section{EXTENDED ABSTACT}

\section{Introduction}

Motivating students is among the most important first steps in ensuring their learning. Classroom activities need to possess certain qualities in order to motivate students and focus their learning. It is very important for the contents of activities, methods for their application and associated end products to be interesting, enjoyable and challenging, while also providing students with opportunities to make choices. Factors such as student interest, enjoyment of topics, and the presence of challenges, and different choices increase both the quality of the learning environment, as well as the motivation of the student. Gentry and Gable (2001) proposed a tool that can measure all of these factors in their Class Activities Scale. A review of the Turkish literature reveals that there are currently no tools that can jointly measure all of these four dimensions. Moreover, the Class Activities Scale has been successfully used in the international literature in a number of different studies (Aryan and Shahrokhi, 2015; Gentry and Gable, 2001; Gentry, Gable and Rizza, 2002; Gentry, Gable and Springer, 2000; Gentry, Rizza and Gable, 2001; Gentry, Rizza and Owen, 2002; Pereira, Peters ve Gentry, 2010; Yang, Gentry ve Choi, 2012). It is evident that an adaptation of this widely used scale would fill an important gap in the Turkish literature, and provide a useful tool for many researchers in different disciplines. This study aims to perform an adaptation of the "Class Activities Scale" to the Turkish culture, including its validity and reliability, allowing measurement of the perceptions of students in their interest and enjoyment of class activities as well as their opportunities for making choices and how much they were challenged during these activities.

\section{Method}

This research is a descriptive study based on a survey method. Descriptive studies attempt to describe and explain "what" events, objects, entities, institutions, groups, and areas are. The study group for the research consists of 214 volunteer students attending grades 3 through 8 in the Mamak Directorate of National Education Büyük Elçi Nazım Belger Primary School and Şehitlik Middle School in Ankara, Çankaya Directorate of National Education Rauf Orbay Primary and Middle schools in Ankara, and Ankara University Development Foundation Primary and Middle schools in Ankara during the 2015-2016 school year. The "My Class Activities Survey" was used as the data collection method in this research. This scale was developed by Gentry and Gable (2001), and attempts to measure perceptions of students regarding their interest in the educational activity, their level of enjoyment, opportunities they had for making choices and how much they were challenged, which are among sub-dimensions that underlie their high level learning. An initial study was conducted as in the Turkish adaptation of the "My Class Activities Survey", including first a translation of the original scale to Turkish, followed by a translation back to English. The first translation was perfomed by a total of four experts, two of which were trained abroad on gifted children, and two of which were trained in foreign languages with doctoral degrees related to gifted children. These experts worked in a panel structure to improve the quality of the translation. 
Subsequently, this translation was evaluated by the researchers. In this evaluation, the most appropriate candidate from among suggested translations for each item in the scale was chosen, or additional alternatives were requested if necessary. As a result of this process, the final form in Turkish consisted of items that were jointly approved by all the experts. The next step of backtranslation to English was performed by three new experts. Together with additional revisions that were found necessary after this step, the first trial version of the form was finalized.

The first pilot application of the scale was performed on 30 students attending the Çankaya Directorate of National Education, Hamdullah Suphi Primary School, identifying and revising items that were not clearly understood. Moreover, opinions from classroom teachers on whether the scale was appropriate for the developmental levels of students were collected during this pilot study, with corresponding revisions performed on the form. As a result, the scale was finalized for the validity and reliability study and was applied to the study group. Following an initial provision of information on the research, volunteer parents and students participated in the study. As explained above, following revisions to the items to improve items that were difficult to understand, the scale was applied to 223 students in Gülen Muharrem Pakoğlu Middle School who had not participated in the pilot study that was performed in the Hamdullah Suphi Primary School.

The analysis of data was performed using SPSS 23 and LISREL 8.7. In studying the validity of the scale, 5 subjects with z scores greater than 2.5 were excluded, being considered as outliers, and 4 subjects were excluded since they had answered all items affirmatively. The analysis was hence performed on a total of 214 students in grades 3 through 8 . In order to determine whether the structure in the original culture could be verified, a Confirmatory Factor Analysis (CFA) was performed and item-total correlations were calculated. Subsequently, Cronbach-alpha reliability coefficient was calculated for sub-dimensions of the scale. As additional evidence for the validity of the study, correlation coefficients between sub-dimensions of the scale were calculated using the Pearson correlation coefficient.

\section{Results and Discussion}

In this research, a Turkish adaptation of the "My Class Activities Survey" developed by Gentry and Gable (2001) in the United States was performed and evidence towards the validity and reliability of the adaptation was provided. In studying the validity of the adaptation, a CFA was performed first, establishing that the adapted scale could be used in Turkey with the same factor structure as the original scale. The goodness-of-fit values obtained from the CFA study showed that the four-factor structure exhibited acceptable fits. Within the factor structure obtained in this fashion, the correlation of each item with the corresponding factor structure was computed using item-total correlations and were found to support the suitability of the structure obtained through the CFA. On the other hand, an investigation of inter-dimensional correlations revealed values that were higher than what would be expected from a scale with sufficiently differentiated dimensions. These high values for interdimensional correlations could be explained with the fact that all items were related to the class activities of students and were hence related to each other. Finally, Cronbach-alpha values for the results were also found to be sufficiently high, supporting the reliability of the scale. 